\title{
CASO DE ENSINO: DECISÕES ESTRATÉGICAS NA GESTÃO DE OPERAÇÕES
}

TEACHING CASE: STRATEGIC DECISIONS IN OPERATIONS MANAGAMENT

Data de submissão: 09/11/2013 Aceite: 01/06/2015

Douglas Wegner ${ }^{1}$ João Carlos Bugs²

\section{RESUMO}

O caso de ensino apresenta a situação hipotética de uma indústria de móveis que enfrenta dificuldades financeiras, decorrentes do aumento na concorrência de mercado e ineficiência na gestão de operações. Um consultor empresarial é contratado para realizar um diagnóstico da gestão de operações da empresa e propor soluções que permitam à empresa melhorar seu resultado com os recursos disponíveis. Este caso tem como objetivo facilitar o processo de ensino-aprendizagem de temas relacionados à Pesquisa Operacional, como programação linear e teoria das restrições, estimulando os alunos a solucionar o problema da empresa e sugerir ações. O caso contribui para o ensino de Administração, à medida que pode ser utilizado para aproximar um conteúdo teórico - a Teoria das Restrições - e uma técnica de solução de problemas - a Programação Linear - da realidade empresarial. Por meio do caso, os alunos tem a oportunidade de discutir e solucionar um problema que retrata a situação de muitas empresas industriais, contribuindo para sua formação profissional.

Palavras-chave: caso de ensino; gestão de operações; teoria das restrições; programação linear; pesquisa operacional.

1 Possui graduação em Administração pela Universidade de Santa Cruz do Sul, Mestrado em Administração pela Universidade Federal de Santa Maria e Doutorado em Administração pela Universidade Federal do Rio Grande do Sul, com período-sanduíche na Universität zu Köln (Alemanha). Professor Adjunto do Mestrado Profissional em Administração da Universidade de Santa Cruz do Sul (UNISC). Santa Cruz do Sul. Rio Grande do Sul. Brasil. E-mail: douglaswegner@hotmail.com

2 Possui graduação em Administração de Empresas pela Universidade de Santa Cruz do Sul, graduação em Ciências Contábeis pela Universidade de Santa Cruz do Sul, Mestrado em Desenvolvimento Regional pela Universidade de Santa Cruz do Sul, e Doutorado em Desenvolvimento Regional pela Universidade Regional de Santa Cruz do Sul. Santa Cruz do Sul. Rio Grande do Sul. Brasil. E-mail: joacarlosbugs@yahoo.com.br 


\section{ABSTRACT}

The teaching case presents the hypothetical situation of a furniture company that faces financial difficulties resulting from an increasing market competition and inefficiency in operations management. A management consultant was hired to diagnose the situation of the company's operations management and propose solutions that may improve its performance with the available resources. The case aims to facilitate the learning process of topics related to Operational Research, as linear programming and the theory of constraints. It encourages students to solve the business problem and suggest actions that help the company to overcome the situation. The case contributes to management education as it can be used to approximate a theoretical content - Theory of Constraints - and a technical troubleshooting - Linear Programming - to a business situation. Through the case students have the opportunity to discuss and solve a problem that portrays the situation of many industrial companies. tional research

Keywords: teaching case; operations management, theory of constraints; linear programming; opera-

\section{INTRODUÇÃO}

\section{Um quebra-cabeças para resolver}

Naquele horário a fábrica já estava silenciosa. As máquinas estavam paradas e os funcionários provavelmente tinham voltado para suas casas. Mesmo os encarregados das áreas, que costumavam ficar após o expediente normal, já tinham saído. O consultor Gustavo Peskow estava sozinho em uma pequena sala, arranjada da melhor forma possível dentro da empresa, para que ele pudesse analisar os relatórios operacionais e propor soluções. Naquele horário ele produzia mais, sem o ruído das máquinas e o burburinho da fábrica. Fazia duas semanas que estava trabalhando naquela consultoria e estava próximo de finalizar a primeira parte. Mas, vamos voltar um pouco no tempo.

\section{Um consultor? Para que?}

A Indústria de Móveis Pereira iniciou suas atividades há quase três décadas, a partir do empreendedorismo de dois jovens irmãos: Pedro e José Pereira. Mesmo estabelecidos em uma pequena cidade do interior gaúcho, os irmãos vislumbraram a oportunidade de produzir móveis em série e atender a um público de classe média, disposto a comprar produtos com uma boa relação custo-benefício. Uma das chaves da longevidade da empresa é que desde o início os fundadores dividiram suas funções e acreditaram na capacidade de cada um, na solução dos problemas em sua respectiva área. Enquanto Pedro se encarregava da área Administrativa, Financeira e Comercial, José atuava na Produção, Compras e Estoques. Com alguma dificuldade, superaram os inúmeros planos econômicos e percalços impostos pela economia brasileira, mantendo a empresa em funcionamento e gerando resultados positivos. Essa capacidade de superar os desafios que haviam deixado tantas empresas pelo caminho parecia aos irmãos Pereira a certeza de que seus conhecimentos e experiência acumulados eram mais do que suficientes para manter o negócio próspero e garantir sua continuidade para a próxima geração. Estavam errados.

A primeira década dos anos 2000 impôs significativos desafios à empresa. Seu mercado regional, antes dividido apenas com pequenas marcenarias de móveis sob-medida, agora era alvo de empresas de diversas partes do país. Empresas de grande porte com alto volume de produção, capaz de entregar móveis com qualidade a preços muito competitivos em praticamente toda a região Sul e Sudeste. Os problemas econômicos de décadas anteriores haviam afetado 
igualmente todas as empresas, mas agora os irmãos Pereira percebiam que a competição acirrada era responsável pelas dificuldades enfrentadas pela empresa. Pela primeira vez Pedro sentia que a gestão de operações da empresa estava deixando a desejar e a perda de eficiência parecia comprometer as finanças do negócio. No passado era possível ganhar dinheiro mesmo sem otimizar os recursos produtivos, mas agora que havia muitos e novos competidores, cada centavo a mais de margem de lucro era fundamental. O problema era que o responsável pela área de produção era seu irmão, José. Além de sócios eram irmãos e nunca era fácil apontar problemas que poderiam ter mais do que consequências profissionais.

Mesmo assim, era preciso agir rápido e tomar decisões. Mais alguns meses de números negativos na última linha do demonstrativo de resultado a empresa teria sérios problemas. Ao circular pela área de produção, Pedro via setores trabalhando à exaustão, enquanto em outros havia funcionários e máquinas parados, além de pilhas de estoques de produtos em processo. Ao mesmo tempo, clientes reclamavam de atrasos na entrega e José afirmava que havia muitos gargalos de produção. Como isso era possível? Será que estavam produzindo os produtos com as melhores margens e que de fato contribuíam para aumentar o resultado do negócio? Algo estava errado, já que o resultado da empresa vinha caindo e nos últimos seis meses estavam no vermelho. Tinha uma proposta para seu irmão José, mas já podia prever a reação: "Contratar um consultor? Para que? Tenho quase 30 anos de experiência coordenando a produção desta fábrica! O que ele poderá nos dizer que eu ainda não sei? E além do mais, já estamos no vermelho e isso significaria mais custos..."

\section{Muitos dados, poucas informações}

Enquanto esperavam a chegada do consultor na sala de reuniões da fábrica, Pedro pensou que, no final das contas, não tinha sido tão difícil assim convencer o irmão a aceitar a contratação da consultoria. José não era orgulhoso ao extremo, mas tinha ficado um pouco chateado com a ideia de ter alguém dando "pitacos" nas suas decisões. Mas, se aquele sujeito realmente pudesse ajudar a encontrar novas soluções para a empresa e otimizar a produção, seria até bom trazer conhecimento novo para a empresa. Além do mais, a situação não estava boa e reverter os números negativos era prioridade, a qualquer custo.

O consultor entrou no prédio da empresa na hora marcada. Gustavo Peskow estava formalmente trajado, mas aos olhos de José pareceu jovem demais para lhe dizer o que devia fazer naquela fábrica. Pedro teve a mesma sensação, e imaginou que o consultor tivesse sido recrutado pela firma diretamente dos bancos escolares. Tinham agendado aquela reunião justamente para repassar ao consultor todos os dados que ele necessitava para auxiliá-los a diagnosticar os problemas na operação da fábrica e encontrar soluções. José encarregou-se de repassar os dados disponíveis sobre a linha de produtos, custos de produção e preços de venda, tempos de produção e recursos disponíveis:

- Atualmente fabricamos três produtos e um total de dez modelos diferentes. Produzimos cinco modelos de roupeiros, dois modelos de cômodas e três modelos de cristaleiras. Nossa linha de produtos era bem maior, mas percebemos que o volume de produção era insuficiente para tantos produtos diferentes. Por um lado, perdemos variedade, o que é ruim para os pontos de venda, mas por outro ganhamos em volume e isso reduziu nossos custos. Como pode ver nesta tabela Sr. Peskow, temos levantamentos atualizados sobre os custos de produção de cada produto. - José entregou uma folha impressa ao consultor. 
Tabela 1: Informações sobre linhas de produtos, preços e custos de produção

\begin{tabular}{|c|c|c|c|c|c|}
\hline \multirow[b]{2}{*}{ Produtos } & \multicolumn{5}{|c|}{$\begin{array}{c}\text { Tabela 1: Informações sobre linhas de produtos, } \\
\text { preços e custos de produção } \\
\text { Elaborada por: Setor de produção e setor finan- } \\
\text { ceiro }\end{array}$} \\
\hline & $\begin{array}{l}\text { Preço de ven- } \\
\text { da por unida- } \\
\text { de (R\$) }\end{array}$ & $\begin{array}{l}\text { Matéria-pri- } \\
\text { ma (R\$) }\end{array}$ & $\begin{array}{l}\text { Mão-de-obra } \\
\text { direta (R\$) }\end{array}$ & $\begin{array}{l}\text { Custos indire- } \\
\text { tos variáveis } \\
\text { (R\$) }\end{array}$ & $\begin{array}{l}\text { Custos vari- } \\
\text { áveis totais } \\
\text { (R\$) }\end{array}$ \\
\hline Roupeiro Modelo 1 & 810,40 & 414,30 & 113,40 & 172,70 & 700,40 \\
\hline Roupeiro Modelo 2 & 711,30 & 405,60 & 113,40 & 92,30 & 611,30 \\
\hline Roupeiro Modelo 3 & 687,65 & 397,05 & 113,40 & 63,20 & 573,65 \\
\hline Roupeiro Modelo 4 & 903,34 & 563,80 & 113,40 & 125,14 & 802,34 \\
\hline Roupeiro Modelo 5 & $1.006,80$ & 575,40 & 113,40 & 198,00 & 886,80 \\
\hline Cômoda Modelo 1 & 458,65 & 184,05 & 97,20 & 57,40 & 338,65 \\
\hline Cômoda Modelo 2 & 346,90 & 107,20 & 97,20 & 57,50 & 261,90 \\
\hline Cristaleira Modelo 1 & $1.064,30$ & 663,50 & 150,90 & 139,90 & 954,30 \\
\hline Cristaleira Modelo 2 & 888,51 & 517,60 & 150,90 & 114,01 & 782,51 \\
\hline Cristaleira Modelo 3 & $1.131,00$ & 691,00 & 150,90 & 199,10 & $1.041,00$ \\
\hline
\end{tabular}

José continuou: - Nossos preços de venda estão sendo constantemente achatados pela concorrência. Até mesmo alguns de nossos melhores parceiros no varejo estão nos pressionando a reduzir preços ou então ameaçam substituir nossos produtos pelos da concorrência. Estes são os preços que estamos praticando atualmente - apontou a primeira coluna da tabela sobre a mesa -, cerca de $5 \%$ inferiores aos do ano passado, tivemos uma inflação anual acumulada de $6 \%$, então você pode imaginar a pressão que o mercado nos impõe. Pelos números você já pode verificar como as nossas margens de contribuição por unidade vendida estão baixas.

- Embora nossa empresa seja relativamente pequena, nos preocupamos em fazer levantamentos periódicos dos tempos de produção de cada modelo. Já tivemos bons avanços nos últimos anos e nossa produtividade aumentou significativamente. Alguns processos que envolviam muita mão-de-obra foram remodelados e parcialmente automatizados. Veja, esta tabela mostra nosso último levantamento de tempos de produção por modelo. - José empurrou mais uma foIha em direção a Peskow. - O processo produtivo é composto por seis modelos de máquinas: $(A)$ Plainadeira, (B) Serra Fita, (C) Serra Circular, (D) Tupia, (E) Coladeira e (F) Pintura Eletrostática. O processo de pintura atende exigências econômicas e técnicas, é ecologicamente correta por não utilizar solventes, e desta forma não produz odores e vapores, preservando o meio ambiente e o profissional envolvido no processo. Então, cada produto percorre um conjunto de máquinas até que esteja concluído e essas máquinas produzem 8 horas por dia, durante 22 dias por mês. 


\begin{tabular}{|c|c|c|c|c|c|c|c|}
\hline \multicolumn{2}{|c|}{$\begin{array}{l}\text { Móveis Pereira } \\
\text { soluções em Móveis }\end{array}$} & \multicolumn{6}{|c|}{$\begin{array}{l}\text { Tabela 2: Processos produtivos } \\
\text { Elaborada por: Setor de produção }\end{array}$} \\
\hline TABELA 2 & \multirow[b]{2}{*}{$\begin{array}{c}\text { Consumo de madeira } \\
\text { por unidade fabricada } \\
\text { em } \mathrm{m} 2\end{array}$} & \multicolumn{6}{|c|}{$\begin{array}{l}\text { Consumo de tempo em cada Máquina } \\
\text { (minutos) }\end{array}$} \\
\hline Produto & & 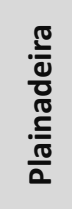 & 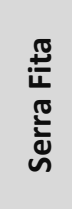 & 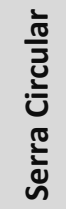 & $\frac{\frac{\pi}{2}}{2}$ & $\begin{array}{l}\frac{\pi}{0} \\
\frac{\pi}{0} \\
\frac{\pi}{0} \\
\end{array}$ & 营 \\
\hline Roupeiro Modelo 1 & 2,2 & 12 & - & 10 & - & 8 & 16 \\
\hline Roupeiro Modelo 2 & 1,8 & 9 & - & 7,5 & - & 8 & 18 \\
\hline Roupeiro Modelo 3 & 1,7 & 10 & - & 7 & - & 7 & 16 \\
\hline Roupeiro Modelo 4 & 1,9 & 12 & - & 6 & - & 8 & 16 \\
\hline Roupeiro Modelo 5 & 2,1 & 6 & - & 8 & - & 11 & 16 \\
\hline Cômoda Modelo 1 & 1,4 & 6 & 6 & - & 36 & 8 & 18 \\
\hline Cômoda Modelo 2 & 1,7 & 7 & 5 & - & 33 & 13 & 20 \\
\hline Cristaleira Modelo 1 & 1,7 & 11 & 8 & 4 & 8 & 8 & 16 \\
\hline Cristaleira Modelo 2 & 1,8 & 10 & 8,5 & 8 & 16 & 7 & 16 \\
\hline Cristaleira Modelo 3 & 2,1 & 9 & 10 & 10 & 30 & 8 & 16 \\
\hline \multicolumn{2}{|c|}{ Quantidade Disponível de Máquinas } & 3 & 1 & 2 & 3 & 3 & 6 \\
\hline
\end{tabular}

- Além disso, temos dificuldades com o volume de madeira para a produção. Por um lado, com nosso espaço para estocagem e nossa limitação financeira é possível armazenar no máximo $6.300 \mathrm{~m}^{2}$ de madeira. Pelo nosso histórico, há uma perda média de $300 \mathrm{~m}^{2}$ de madeira por mês. Sempre há peças de madeira que não podem ser utilizadas na sua totalidade e também ocorrem perdas durante o processo de fabricação, de maneira que contamos com no máximo $6.000 \mathrm{~m}^{2}$ disponíveis para produção.

O traje formal do consultor parecia fora de contexto naquela sala acanhada e de móveis antiquados - o que era uma contradição para uma indústria daquele setor. Peskow tinha o perfil que se espera de um consultor: sabia ouvir e falava pouco. Fora treinado para fazer perguntas e obter as informações que precisava para o seu trabalho. Ainda que fizesse muitas perguntas, seu comportamento não denotava arrogância. - Sr. José, o senhor comentou que a indústria tem parcerias com varejistas e que a empresa precisa atender demandas de mercado? Quero dizer, precisa produzir quantidades mínimas para fornecer aos seus parceiros ou para atender pedidos mensais?

- Atualmente temos alguns pedidos fixos que não podemos deixar de atender. Se deixarmos de entregar essas quantidades, corremos o risco de ter os contratos de compra cancelados. No futuro poderemos até renegociar esses contratos, mas no momento precisamos entregar, seja isso bom ou ruim. Na verdade deixar de fazer essas entregas seria impensável para a empresa e nos levaria a perder esses clientes, já que eles compram todos os produtos da nossa linha. Por outro lado, nosso setor de vendas faz levantamentos frequentes do mercado e verificamos que, para alguns produtos, existe uma demanda máxima. Então podemos produzir no máximo essas quantidades, porque do contrário vamos ficar com produtos estocados e isso aumentaria a pressão sobre nosso fluxo de caixa. 
Tabela 3: Produção mínima e máxima mensal

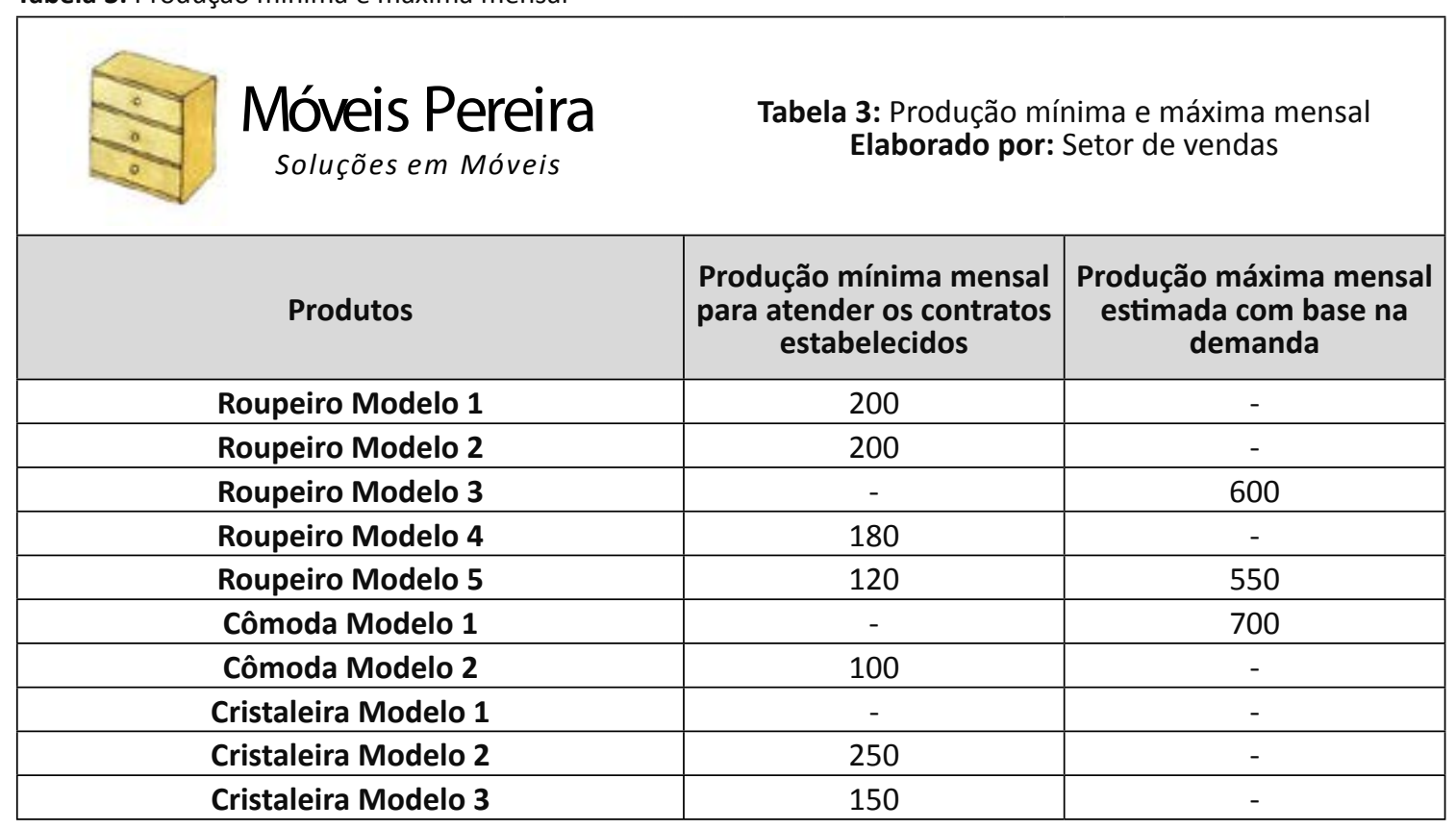

\section{Como otimizar os resultados?}

Peskow continuava imerso em pensamentos, na acanhada sala que lhe fora reservada. Nem tinha percebido as horas passarem, mas finalmente começava a ter mais clareza sobre o que precisava ser feito. A fábrica estava produzindo sem foco e era urgente estabelecer uma programação da produção que otimizasse a margem de contribuição, ainda que isso significasse reduzir a produção de alguns modelos ao mínimo necessário para atender os clientes. Era evidente que a empresa possuía recursos limitados, cuja utilização precisava ser otimizada. Decidiu utilizar ferramentas de programação linear e elaborar um relatório gerencial que permitisse à empresa reorganizar sua produção, eliminar gargalos e maximizar seus resultados.

O consultor sabia que o sucesso da sua consultoria aos irmãos Pereira estava vinculado à sua capacidade de oferecer informações úteis, mas principalmente, mostrar a eles como chegar às próprias conclusões utilizando ferramentas de gestão. Talvez seu maior desafio fosse justamente convencê-los da importância de tomar decisões com base em informações concretas, não apenas com base na experiência ou na intuição. Esse era, de fato, o resultado mais importante que aquela consultoria poderia atingir. Era hora de arregaçar as mangas e preparar um relatório convincente para apresentar no dia seguinte.

Coloque-se no papel do consultor e analise a situação da empresa utilizando ferramentas de Pesquisa Operacional. Após, elabore um relatório para apresentar aos irmãos Pereira, contemplando as seguintes seções:

a) Solução do problema: elabore o modelo matemático do problema apresentado (Variáveis, Função Objetivo e Restrições) e solucione o modelo por meio da técnica de Programação Linear, utilizando o aplicativo Microsoft Excel/Solver. 
b) Diagnóstico: Utilize a Teoria das Restrições para analisar a situação, identificando os gargalos, riscos operacionais e problemas que a empresa enfrenta atualmente, utilizando dados concretos para justificar suas conclusões.

c) Possíveis causas: indique os possíveis fatores (operacionais, tecnológicos, financeiros, gerenciais) que dão origem a cada um dos problemas identificados. Cada problema pode ter mais de uma hipótese que explica sua ocorrência; certifique-se que as causas mais prováveis foram identificadas;

c) Plano de ação: elabore um plano de ação que os gestores da empresa poderiam adotar para minimizar os problemas e maximizar os resultados, utilizando a ferramenta $5 \mathrm{~W} 2 \mathrm{H}^{3}$. Estabeleça uma relação entre cada problema identificado, as possíveis causas e as ações sugeridas.

\section{NOTAS DE ENSINO}

\section{Sinopse:}

O caso apresenta a situação de uma empresa do ramo de móveis que enfrenta dificuldades financeiras, decorrentes do aumento na concorrência de mercado e ineficiência na produção. Com a ajuda de um consultor, os proprietários da empresa querem analisar a área de operações, identificando problemas e suas causas, planejando ações que permitam tornar a empresa mais eficiente e obter melhores resultados financeiros. Com base nas informações fornecidas pela empresa sobre a linha de produtos, preços de venda, custos, tempos de produção e condições de mercado, os alunos podem utilizar ferramentas de programação linear para solucionar o problema e sugerir ações à empresa.

\section{Utilização recomendada}

O caso foi elaborado para utilização em disciplinas de graduação e pós-graduação relacionadas à tomada de decisão na área de operações. Possibilita também, a disposição de informações relevantes para a elaboração de planejamento de produção e de vendas.

\section{Objetivos de Aprendizagem}

A ênfase é dedicada à elaboração de diagnósticos organizacionais por meio da utilização da Pesquisa Operacional, em especial a técnica de programação linear. Com o caso, os alunos podem desenvolver competências relacionadas ao diagnóstico de problemas organizacionais, elaborar hipóteses para as causas desses problemas e sugerir soluções. O professor pode, ainda, trabalhar conceitos da Teoria das Restrições como gargalos de produção e método de solução de problemas. O caso busca estimular a capacidade de análise e de proposição de soluções dos alunos. Além da discussão teórica, o caso possibilita que os alunos exercitem a aplicação da técnica $5 \mathrm{~W} 2 \mathrm{H}$, amplamente utilizada na gestão organizacional para elaboração de planos de ação e posterior controle e verificação da sua implementação. A denominação $5 \mathrm{~W} 2 \mathrm{H}$ refere-se a sete palavras em inglês que caracterizam a técnica: 1) What? O que fazer? 2) Why? Por quê fazer? 3)

3 5W2H é uma ferramenta utilizada para elaboração de planos de ação, para que haja a maior clareza possível sobre como executar determinadas ações. A denominação refere-se a sete palavras em inglês que caracterizam a ferramenta: 1) What? O que fazer? 2) Why? Por quê fazer? 3) Who? Quem deve fazer? 4) Where? Onde deve ser feito? 5) When? Quando deve ser feito? 6) How? Como deve ser feito? 7) How much? Quanto custa? O plano de ações pode ser apresentado em forma de tabela. 
Who? Quem deve fazer? 4) Where? Onde deve ser feito? 5) When? Quando deve ser feito? 6) How? Como deve ser feito? 7) How much? Quanto custa?

\section{Embasamento teórico}

\subsection{Pesquisa Operacional}

A denominação Pesquisa Operacional apareceu durante a Segunda Guerra quando pesquisadores foram solicitados a desenvolver métodos para a resolução de determinados problemas operacionais para os militares. Conforme Silva et al. (2010), a Pesquisa Operacional consiste em um conjunto de métodos científicos de tomada de decisões. Em linhas gerais, consiste na descrição de um sistema organizado com o auxílio de um modelo matemático e, através da experimentação com o modelo, na descoberta da melhor maneira de operar o sistema. $O$ sucesso obtido na implementação das diversas técnicas como programação linear, teoria dos jogos, programação dinâmica, PERT/CPM, teoria das filas, simulação, fez com que o mundo acadêmico e empresarial utilizasse a Pesquisa Operacional para a resolução de casos e problemas de administração.

\subsubsection{Programação Linear}

Com o surgimento do computador, a programação linear teve o seu desenvolvimento acelerado e difundido nos meios empresariais e acadêmicos. Segundo Prado (2007, p. 16) a programação linear é uma técnica de otimização, sendo uma ferramenta utilizada para encontrar o lucro máximo ou o custo mínimo em situações nas quais há diversas opções de escolha sujeitas a algum tipo de restrição ou regulamentação. Portanto, a programação linear é uma técnica de planejamento que tem sua base na matemática e economia, permitindo identificar os gargalos de um sistema e propor soluções.

\subsection{Teoria das Restrições}

A Teoria das Restrições - TOC (Theory of Constraints) foi desenvolvida a partir da década de 1970 pelo físico Israelense Eliyahu Goldratt, o qual elaborou um método novo de administração da produção, onde a chave para saber o que fazer em um determinado sistema é verificar o papel que as restrições têm no processo (GOLDRATT e COX, 1997). Segundo Cox III e Spencer (2002), através do desenvolvimento do chamado processo de pensamento da Teoria das Restrições, Goldratt propôs a possibilidade de generalizações dos conceitos originais sobre a gestão da função de produção. Desta forma, a ideias de TOC vêm sendo gradualmente desenvolvidas e adotadas em outras áreas empresariais como marketing, finanças, vendas e logística industrial. Simultaneamente, o processo de pensamento da TOC pode ser utilizado como uma potente ferramenta de estruturação, identificação, análise e solução de problemas completamente embasada no chamado método dialético.

Ainda conforme Cox III e Spencer (2002, p.71-74), a teoria apresenta cinco etapas de focalização no gerenciamento de restrições:

1a. Identificar a restrição do sistema: Consiste em identificar a restrição no sistema que limita o ganho, já que o desempenho do sistema como um todo depende disso.

2a. Como explorar a restrição do sistema: Significa aproveitar a capacidade existente na restrição que, frequentemente, é desperdiçada por se produzir e vender os produtos errados ou por causa da utilização de regras e procedimentos inadequados para programar e controlar a res- 
trição. Como cada minuto perdido no recurso crítico é perdido por todo o sistema, é fundamental fabricar o composto de produtos correto e manter o fluxo para a restrição durante todo o tempo.

3a. Subordinar tudo o mais à restrição do sistema: Todas as outras atividades devem ser subordinadas à restrição. É a etapa mais difícil porque questiona todas as práticas e procedimentos gerenciais tradicionais, além dos indicadores locais.

4a. Elevar a restrição do sistema: Significa aumentar a capacidade para um nível mais alto. Isso normalmente é feito através de modificações em equipamentos existentes e usando velocidades ou alimentadores mais altos ou acrescentando mais capacidade em equipamentos ou recursos.

5a. Evitar a inércia: Representa não interromper o processo de aprimoramento contínuo. Os gerentes são desafiados a planejar continuamente a melhoria do desempenho da organização global focalizando em ações que provoquem a melhoria do desempenho da restrição. Com isto, a melhoria contínua é definida como um movimento em direção à meta da organização, que é ganhar mais dinheiro hoje e no futuro.

\section{Solução do caso utilizando a Programação Linear}

\subsection{Elaboração do modelo matemático}

A Pesquisa Operacional é um método para a otimização, e uma das técnicas mais utilizadas na abordagem de problemas é a Programação Linear. A simplicidade do modelo envolvido e a disponibilidade de uma técnica de solução programável em computador facilitam sua aplicação. Segundo Prado (2007, p.16) a Programação Linear é uma ferramenta utilizada para encontrar o lucro máximo ou o custo mínimo em situações nas quais temos diversas opções de escolha sujeitas a algum tipo de restrição ou regulamentação, permitindo identificar gargalos de produção e problemas relacionados à gestão de operações.

\section{a. Variáveis de Decisão}

Aqui o trabalho consiste em explicitar as decisões que devem ser tomadas e representar as possíveis decisões através de variáveis chamadas variáveis de decisão. Se o problema é de programação de produção, as variáveis de decisão são as quantidades a produzir no período.

RM1 - Quantidade mensal a produzir do Roupeiro Modelo 1

RM2 - Quantidade mensal a produzir do Roupeiro Modelo 2

RM3 - Quantidade mensal a produzir do Roupeiro Modelo 3

RM4 - Quantidade mensal a produzir do Roupeiro Modelo 4

RM5 - Quantidade mensal a produzir do Roupeiro Modelo 5

CM1 - Quantidade mensal a produzir da Cômoda Modelo 1

CM2 - Quantidade mensal a produzir da Cômoda Modelo 2

CrM1 - Quantidade mensal a produzir da Cristaleira Modelo 1

CrM2 - Quantidade mensal a produzir da Cristaleira Modelo 2

CrM3 - Quantidade mensal a produzir da Cristaleira Modelo 3 


\section{b. Função-Objetivo}

Consiste em identificar o objetivo da tomada de decisão. Aparece geralmente na forma da maximização de lucros ou receitas, minimização de custos, perdas. A Função Objetivo é a expressão que calcula o valor do objetivo (lucro, custo, receita, perda, distância, quantidade, etc), em função das variáveis de decisão. No presente caso, é necessário calcular a margem de contribuição unitária de cada produto, com base no preço de venda e custos variáveis apresentados na Tabela 1.

Função-Objetivo MAX = 110 RM1 + 100 RM2 + 114 RM3 + 101 RM4 + 120 RM5 + 120 CM1 + 85 $\mathrm{CM} 2+110 \mathrm{CrM} 1+106 \mathrm{CrM} 2+90 \mathrm{CrM} 3$

\section{c. Restrições}

Representam as limitações do sistema. Cada restrição imposta na descrição do sistema deve ser expressa como uma relação linear (igualdade ou desigualdade), montadas com as variáveis de decisão.

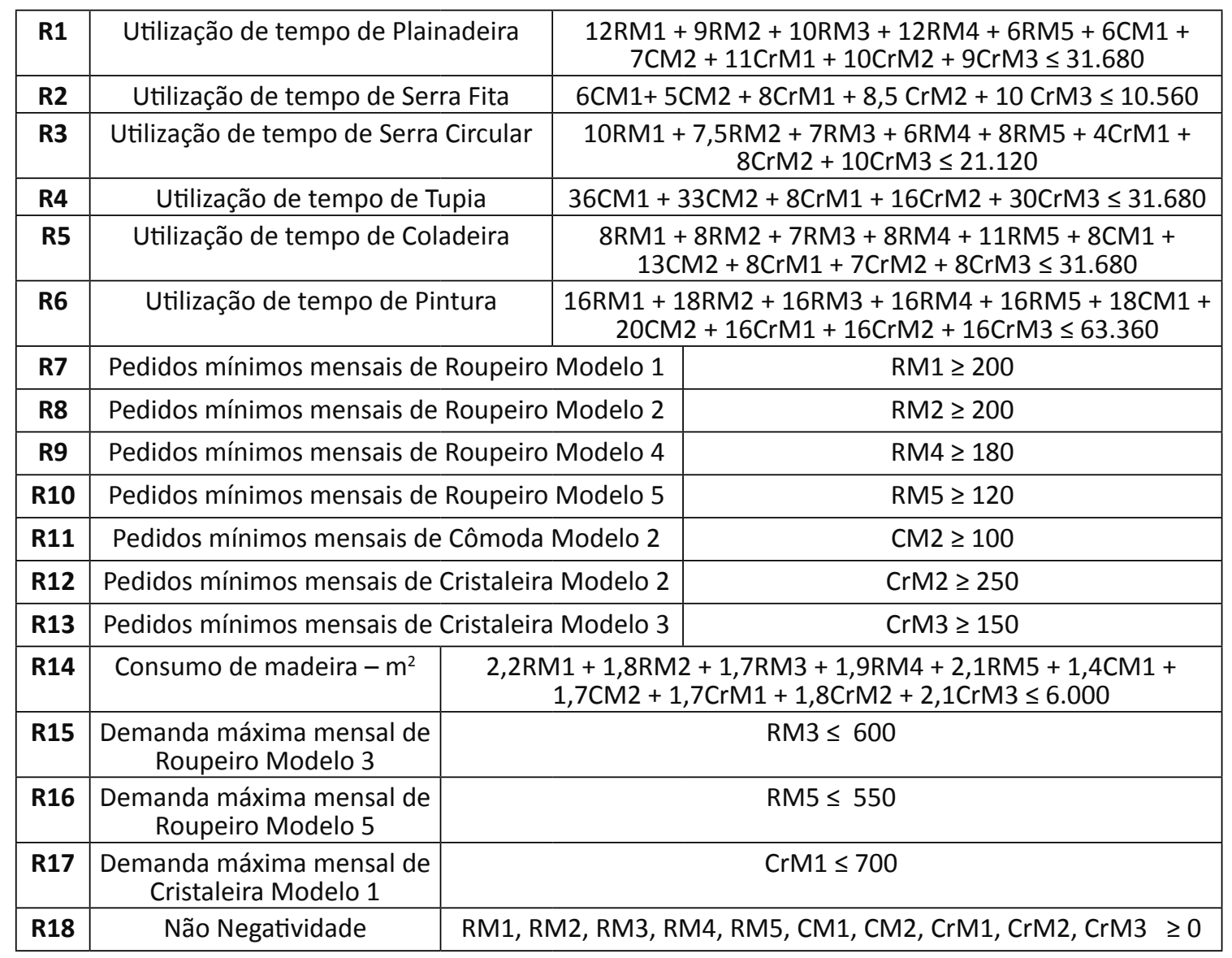




\subsection{Solução utilizando planilha eletrônica}

Uma vez que o modelo matemático de Programação Linear tenha sido elaborado, o problema pode ser solucionado utilizando planilha eletrônica e aplicativo específico, como o Solver, que se encontra instalado como suplemento do Microsoft Excel. Na sequência, apresenta-se um roteiro básico para inserção dos dados no Excel e solução do problema. Para aprofundamentos sobre a utilização do Solver, sugere-se consultar Lachtermacher (2004).

\section{Passo: Inserção dos dados na planilha Excel}

Deve-se criar um modelo na planilha Excel que possibilite detalhar as informações de uma forma bem clara, compreensível e prática. Para tanto, é muito importante dar nomes adequados às Variáveis, à Função-Objetivo e às Restrições, os quais servirão de orientação para a análise posterior dos resultados.

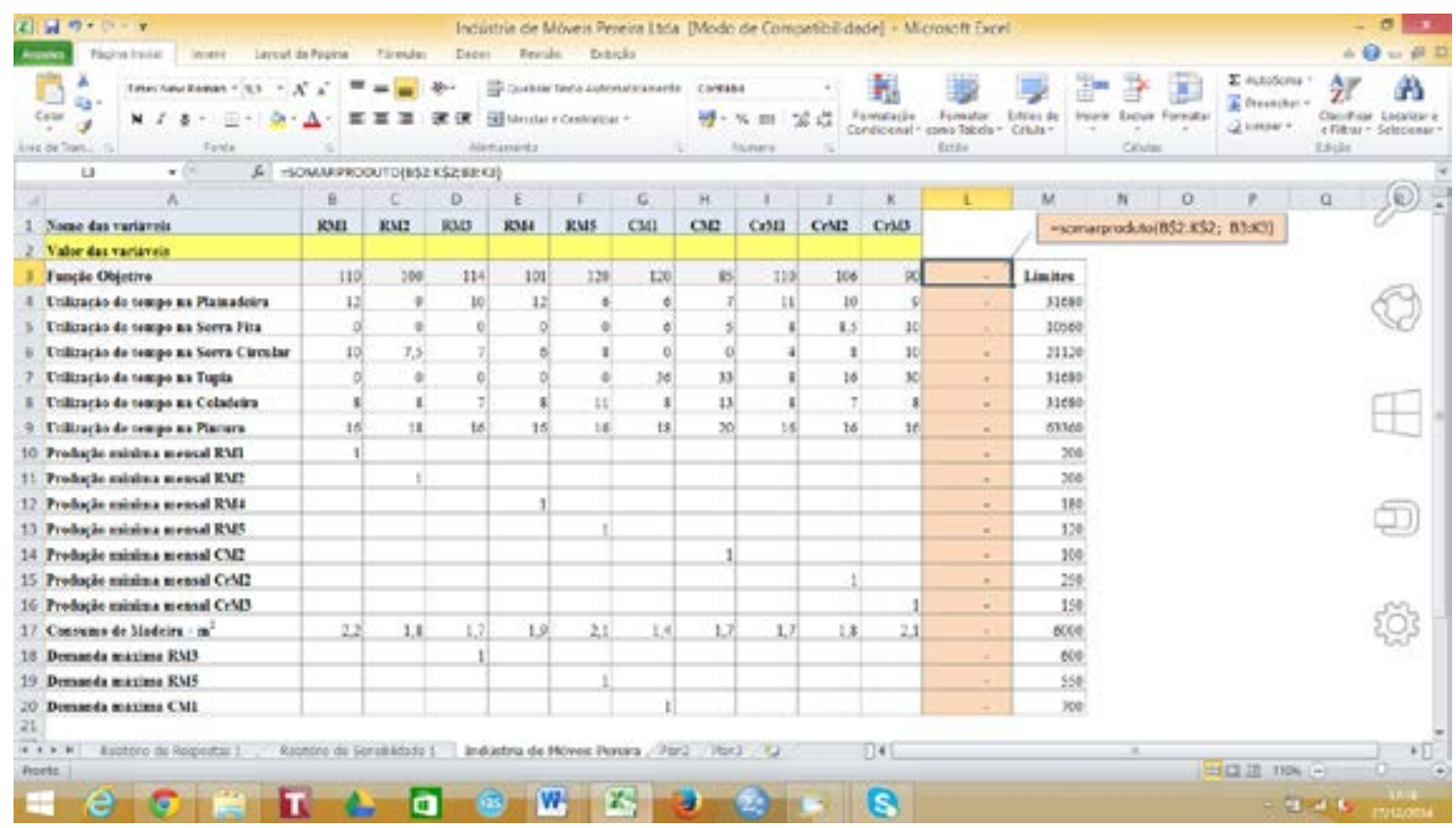

\section{Passo: Abrir o Solver e inserir os parâmetros}

a. Na tela de entrada do Excel, clicar em "Dados";

b. Posteriormente, clicar em Solver;

c. Com isto, abre a tela "Parâmetro do Solver".

d. Na tela de parâmetros, deve-se informar a célula destino (neste caso a célula L3 da planilha do Excel, onde foi inserida a fórmula), as células das variáveis (em branco na planilha do Excel) e adicionar as restrições do modelo. Também deve ser selecionado um método de solução, neste caso LP Simplex.

e. Informar a condição de não negatividade das variáveis;

f. Informados os parâmetros, clicar em "Resolver". 


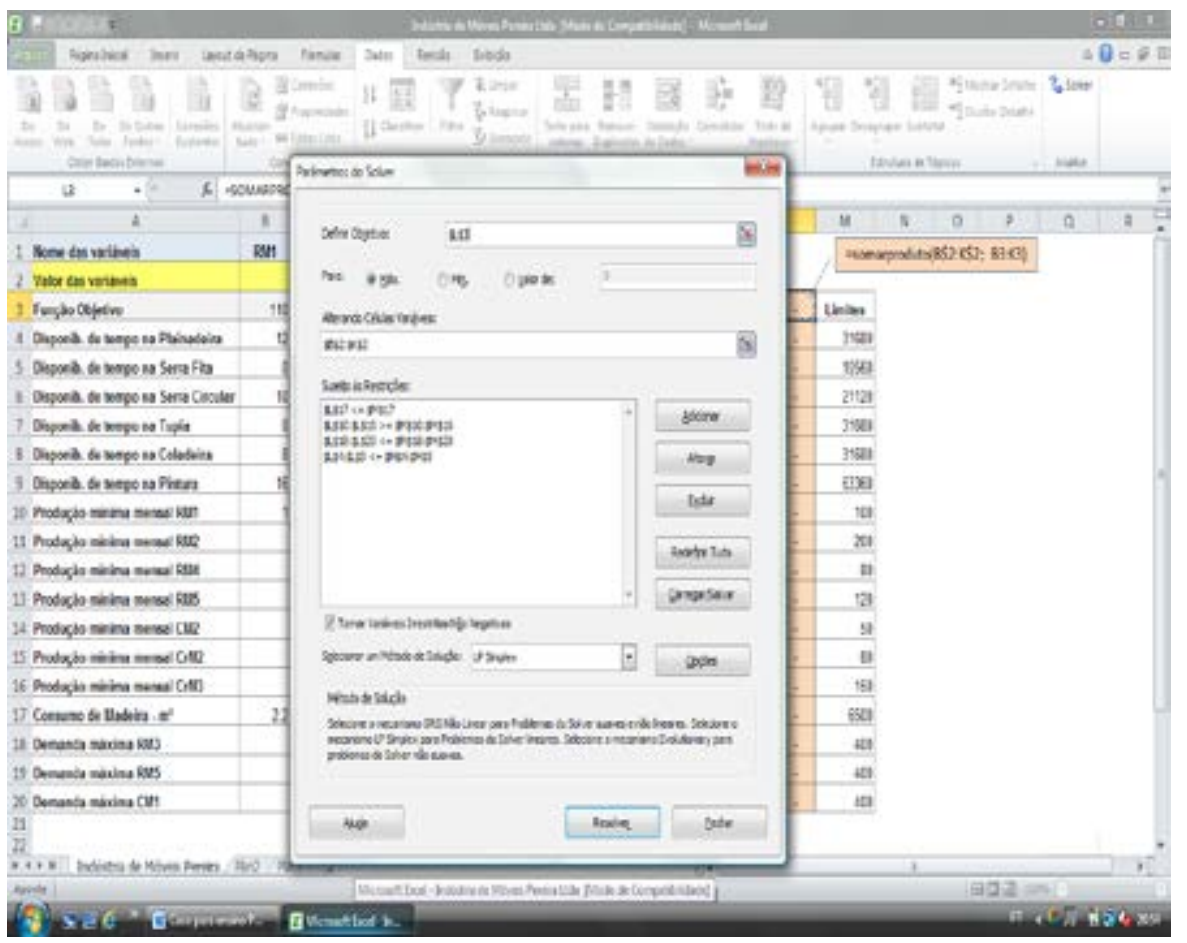

\section{3o Passo: Relatórios e interpretação}

Clicar na opção "Resolver" e o resultado aparecerá na tela do Excel, (Célula L3), bem como abrirá a tela "Resultados do Solver". Na tela Resultados do Solver, marcar no quadro Relatórios as opções "Resposta" e "Sensibilidade", e clicar OK.

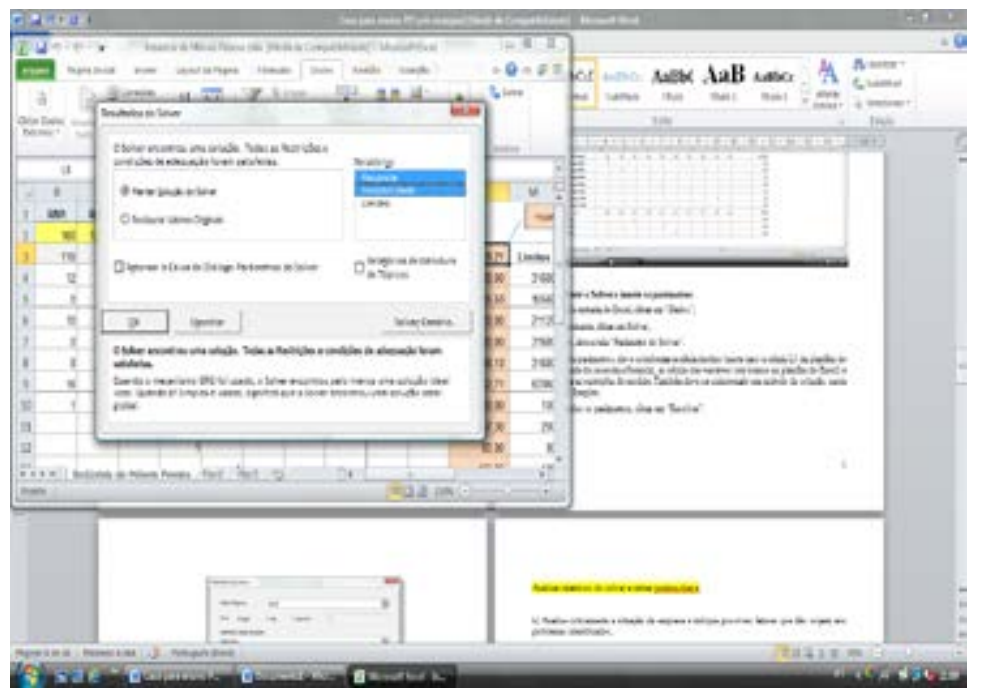

Nesse momento serão gerados os relatórios solicitados, que estarão disponíveis como novas planilhas do Excel e poderão ser consultados. 


\section{Elaborando o relatório da consultoria}

O relatório da consultoria com as três seções propostas ao final do caso de ensino pode ser elaborado com base nos relatórios de resposta e sensibilidade gerados pelo Solver e apresentados nos Anexos A e B. Algumas sugestões de análise são apresentadas na sequência:

a) Diagnóstico. Considerando a atual disponibilidade de recursos produtivos, para maximizar a geração de margem de contribuição, a empresa deve produzir 200 unidades de RM1, 380 unidades de RM2, 600 unidades de RM3, 180 unidades de RM4, 550 unidades de RM5, 448 unidades de CM1, 100 unidades de CM2, 4368 unidades de CrM1, 250 unidades de CrM2 e 150 unidades de CrM3 (conforme Relatório de Respostas - Células Variáveis - Valor Final).

Com base nos relatórios do Solver e informações do caso de ensino, é possível identificar os seguintes gargalos e problemas enfrentados pela empresa:

a1) Os gargalos de produção encontram-se nos setores da Serra Fita e da Tupia, cuja disponibilidade de tempo foi completamente consumida (conforme Relatório de Respostas - Células Variáveis - Margem de Atraso). Os demais setores possuem sobra de tempo, demonstrando que a fábrica não está equilibrada;

a2) A madeira disponível foi consumida (conforme Relatório de Respostas - Células Variáveis - Margem de Atraso igual a zero) e a margem de contribuição total poderia ser ampliada se houvesse madeira adicional (conforme Relatório de Sensibilidade - Restrições - Sombra Preço da madeira igual a $\mathrm{R} \$ 55,56)$. Isso significa que cada $\mathrm{m}^{2}$ adicional de madeira que a empresa pudesse dispor ampliaria a margem de contribuição total em $R \$ 55,56$, até um limite de $291 \mathrm{~m}^{2}$ adicionais;

a3) Conforme enunciado do problema, a empresa possui limitação de espaço físico para estocagem de madeira e falta de recursos financeiros, não sendo possível adquirir mais do que $6.300 \mathrm{~m}^{2}$ da matéria-prima. Outro problema refere-se à perda de $300 \mathrm{~m}^{2}$ de madeira entre o volume recebido e o volume efetivamente aproveitado na produção.

a4) Dos sete contratos de produção mínima que a empresa possui com clientes, cinco são desvantajosos e não contribuem para maximizar a margem de contribuição total (conforme Relatório de Sensibilidade - Restrições - Sombra Preço). Isso se verifica porque a produção de unidades adicionais desses produtos geraria impacto negativo para a FO. Pode-se depreender que, ao fabricar esses produtos, a empresa está utilizando recursos produtivos que poderiam ser utilizados para fabricação de outros produtos, que geram maior contribuição financeira.

b) Possíveis causas. Com base nos problemas identificados, podem ser elencados fatores que contribuem para sua ocorrência. É importante destacar que não existem respostas únicas, sendo responsabilidade dos alunos identificarem hipóteses coerentes.

b1) Os gargalos nos setores da Serra Fita e da Tupia podem estar associados a diversos fatores, como: falta de máquinas (considerando que os setores estão operando com a máxima eficiência possível), obsolescência das máquinas (produzem com eficiência inferior a máquinas mais modernas), falta de manutenção (ocasiona paradas na produção e perdas de eficiência), baixa qualificação dos operadores das máquinas (ocasiona perda de eficiência), desmotivação dos funcionários (devido a políticas de gestão de pessoas). Entre as duas máquinas, a que pode gerar maior aumento no resultado da empresa é a Tupia, cujo preço-sombra é de 1,02, indicando 
que cada minuto adicional disponível nesse setor aumentará o resultado da empresa em $R \$ 1,02$, até um limite de 7.555 minutos;

b2) A falta de recursos financeiros para compra de madeira e espaço físico para estocagem são as causas para a falta de toda a matéria-prima;

b3) As causas para a perda de $300 \mathrm{~m}^{2}$ de madeira entre o volume adquirido e efetivamente aproveitado podem ser a qualidade do produto (consta que algumas peças chegam com defeito e não podem ser utilizadas) e o uso inadequado da madeira no processo de fabricação, devido à obsolescência das máquinas ou falta de treinamento dos funcionários.

b4) Os contratos com clientes, que preveem entrega de quantidades mínimas, podem ter sido firmados em um cenário favorável no passado, mas atualmente impactam negativamente no resultado da empresa. A má negociação dos contratos é a causa provável para esse problema.

c) Plano de ação. Sugere-se que os alunos façam a conexão entre os problemas identificados, as possíveis causas e elaborem ações que permitam melhorar o resultado da empresa, como exemplificado na tabela abaixo. Destaca-se que as ações apresentadas não esgotam as possibilidades de análise do caso. Os alunos têm a possibilidade de apresentar soluções, cabendo ao professor analisar se essas ações são coerentes com os problemas identificados e suas prováveis causas (ver exemplo na Tabela 4).

\section{Abordagem de ensino}

Recomenda-se que o caso seja utilizado como recurso didático para aulas cujos temas centrais são: capacidade de produção, análise de gargalos no processo, análise das dificuldades de fluxo de caixa, falta de capital de giro. É importante que os alunos tenham noções adequadas sobre Programação Linear, fluxo de processos e gestão de operações.

Como sugestão ao Professor, os trabalhos poderão ser desenvolvidos utilizando a seguinte ordem:

a. Leitura do caso, revisão e esclarecimento dos conceitos sobre Programação Linear, fluxo de processos e gestão de operações.

b. Divisão dos alunos em pequenos grupos para análise das decisões e resolução através da técnica de Programação Linear.

c. Apresentação pelos grupos dos relatórios de consultoria, com ênfase para as conexões entre problemas identificados, suas causas e sugestões de ações para cada problema.

d. Fórum de discussão das alternativas levantadas pelos grupos e apresentação dos questionamentos, visando o aprimoramento através da ampliação no conjunto de conhecimentos. 


\section{REFERÊNCIAS}

Programação Linear - Processo de Modelagem

COX III, J. F.; SPENCER, M. S. Manual da Teoria das Restrições. Prefácio de Eliyahu M. Goldratt. Porto Alegre: Bookman, 2002.

SILVA, E. M.; SILVA, E. M.; GONÇALVES, V.; MUROLO, A. C. Pesquisa Operacional: para os cursos de Administração e Engenharia. São Paulo: Atlas, 2010. p.1 e p.179-186.

Cálculo da margem de contribuição

ASSEF, R. Guia prático de administração financeira: pequenas e médias empresas. Rio de Janeiro: Campus, 1999. p. 41-42.

BRUNI, A. L.; FAMÁ, R. Gestão de Custos e Formação de Preços. 5. ed. São Paulo: Atlas, 2008. p. 216, 264.

Programação Linear - Solução através do Excel/Solver

LACHTERMACHER, G. Pesquisa Operacional na Tomada de Decisões. Modelagem em Excel. 2. ed. Rio de Janeiro: Elsevier, 2004. p.133-159.

CORRAR, L.J.; THEOPHILO, C.R. Pesquisa Operacional. São Paulo: Atlas, 2003.

Teoria das restrições

GOLDRATT, E. M.; COX, J. A Meta. São Paulo: Educator, 1997.

SOARES, I.H.L.; ARMOND-DE-MELO, D.R.; LEOPOLDINO, C.B.; ABREU, J.C.A.; MOITA, F.M. A Teoria das Restrições em um processo de fabricação da indústria na construção civil: Um estudo de caso. Revista de Administração da UFSM, v. 2, n. 3, pp. 463-478, 2009.

Gestão de empresas familiares

FREITAS, E.C.; BARTH, M. De pai para filho: a complexidade e os desafios da gestão das empresas familiares. Revista de Administração da UFSM, v. 5, n. 3, pp. 549-468, 2012.
BELMONTE, V.A.B.; FREITAS, W.R.S. Empresas familiares e a profissionalização da gestão: Estudo de casos em empresas paulistas. Revista de Administração da UFSM, v. 6, n. 1, pp. 71-90, 2013. 